Revista Chilena
DE Pediatría

www.revistachilenadepediatria.cl

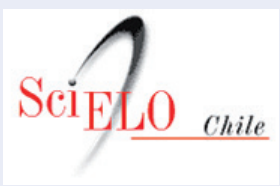

www.scielo.cl

\title{
COVID-19 en América Latina: Retos y oportunidades
}

\section{COVID-19 in Latin America: Challenges and opportunities}

\author{
Reinaldo Pierre Alvarez ${ }^{\mathrm{a}, \mathrm{b}}$, Paul R Harris ${ }^{\mathrm{c}}$
}

aClínica Razetti - IDB Medical Group, Universidad Central de Venezuela, Barquisimeto, Venezuela. bPresidente Sociedad Latinoamericana de Gastroenterología, Hepatología y Nutrición Pediátrica (SLAGHNP/LASPGHAN). ‘Departamento de Gastroenterología y Nutrición Pediátrica, Pontificia Universidad Católica de Chile, Santiago, Chile.

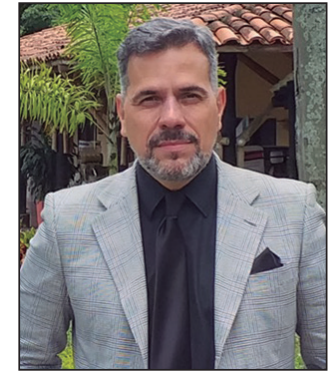

Reinaldo Pierre Alvarez
COVID-19 (Coronavirus Disease 2019), la enfermedad provocada por el virus SARS-CoV-2, declarada pandemia global por la Organización Mundial de la Salud (OMS) el 11 de Marzo de 2020', comienza a acelerar su propagación en América. Estados Unidos supera ya los 100,000 casos y los 1,500 fallecidos, mientras que en América Latina se reportan hasta el momento más de 10,000 casos confirmados y una tasa creciente de muertes (figura 1). Las experiencias de China, Corea del Sur, el comportamiento actual de la pandemia en Estados Unidos y en algunos países europeos, deben ser analizados y tomados en consideración como señales de alarma frente a lo que podría suceder a corto plazo en nuestra región.

\section{COVID-19}

Desde un punto de vista estrictamente biológico, el SARS-CoV-2 es un RNA-virus perteneciente al género Betacoronavirus que fue aislado en Enero de este año a raíz de un brote de neumonía de "causa desconocida" identificado en Wuhan, China ${ }^{2}$. El virus pertenece a una gran familia que puede causar desde afecciones respiratorias leves hasta formas más severas como el Síndrome Respiratorio de Oriente Medio (conocido por sus siglas en inglés MERS) y el Síndrome Respiratorio Agudo Severo (conocido por sus siglas en inglés SARS). Los síntomas más comunes son fiebre $(80 \%)$, tos seca $(70 \%)$, dificultad respiratoria $(40 \%)$ y otros tales como malestar general, mialgias, artralgias, cefalea, anosmia y disgeusia ${ }^{2}$. Desde el punto de vista gastrointestinal, un estudio descriptivo, multicéntrico realizado en China reveló que hasta el $48,5 \%$ de los pacientes (adultos) evaluados en tres hospitales de ese país durante los meses de Enero y Febrero, consultaron inicialmente por síntomas digestivos (diarrea, vómitos, dolor abdominal e hiporexia) y que la presencia de estos estuvo asociada con una estancia hospitalaria más prolongada y un peor pronóstico ${ }^{3}$. Los mismos síntomas pueden encontrarse hasta en el 10\% de los pacientes pediátricos ${ }^{4}$. En relación a estos últimos, la evidencia sugiere que los niños se infectan menos y cuando lo hacen, lo hacen de forma menos severa. Una revisión de 72.314 casos publicada por el Centro Chino de Control y Prevención de Enfermedades, demostró que menos del $1 \%$ de los casos correspondieron a pacientes menores de 10 años ${ }^{5}$. En otra serie de casos, la evaluación de 171 niños en Wuhan, China, demostró que alrededor del 16\% de los pacientes permanecieron asintomáticos sin alteraciones radiológicas evidentes durante la infección. Hasta la fecha y de acuerdo

Correspondencia:

Reinaldo Pierre Alvarez

vice.presidencia.laspghan@gmail.com 
Figura 1. Casos de COVID-19 confirmados por países y Continentes, al 29 de Marzo de 2020. Modificado de PAHO y John Hopkins University CSSE.

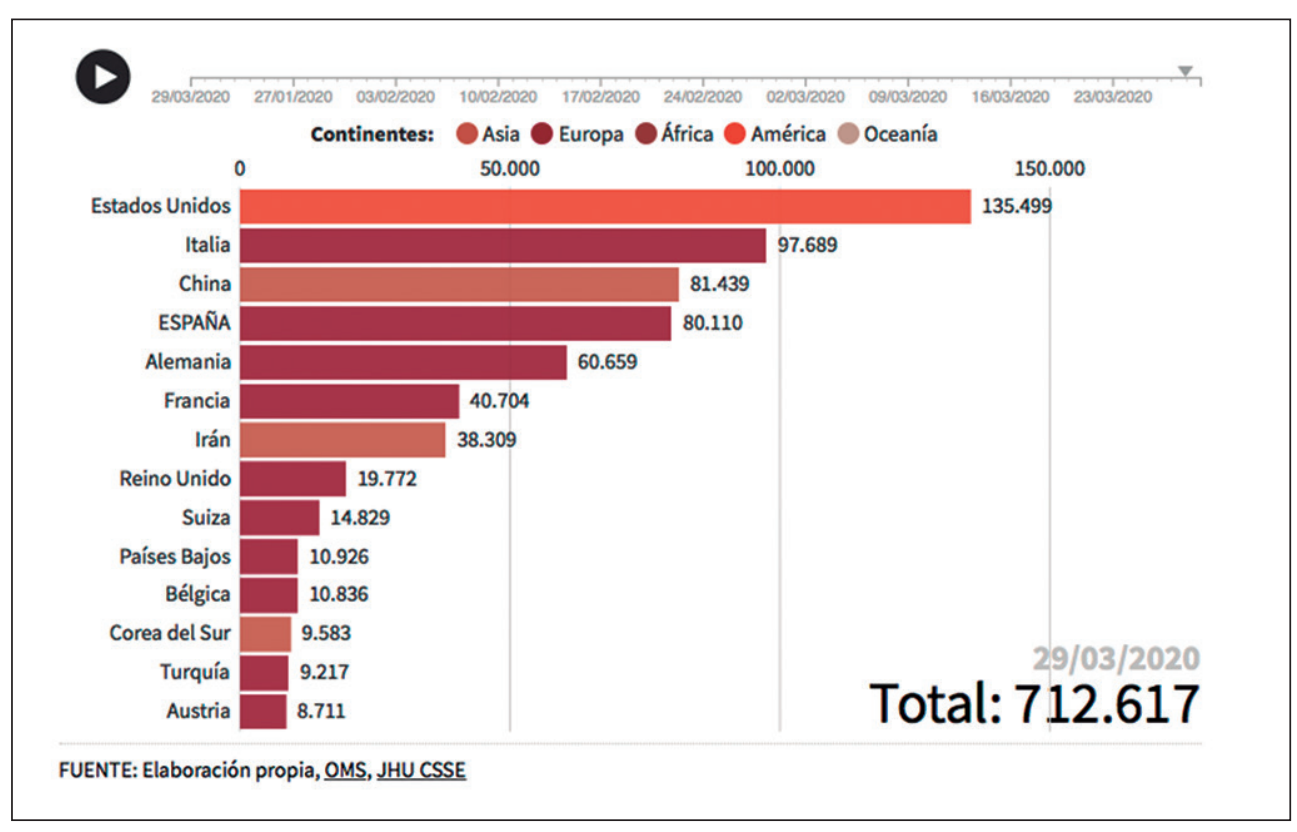

a la información disponible, los pacientes pediátricos diagnosticados con COVID-19 pueden desarrollar en general desde cuadros clínicos respiratorios leves no complicados (la mayoría) hasta Síndrome de distress respiratorio agudo (SDRA) ${ }^{6}$. Los mecanismos identificados de transmisión y el elevado potencial de contagio a partir de pacientes pediátricos y adultos asintomáticos u oligosintomáticos justificaría las medidas de higiene extrema, cuarentena, aislamiento y distanciamiento social que constituyen parte de la campaña emprendida a nivel mundial para frenar el avance de la pandemia. Estas medidas han incluído entre otras, la suspensión de actividades escolares, lo cual ha generado en América latina y el Caribe una crisis educativa sin precedentes con alrededor de 154 millones de niños y adolescentes, que representan más del 95\% del matriculado, fuera de las aulas, según cifras oficiales de UNICEF.

\section{Situación actual de COVID-19 en América Latina}

El primer caso "latinoamericano" de COVID-19 se registró en Brasil el 26 de Febrero y la primera muerte por la infección en la región se anunció en Argentina el 7 de Marzo. Si bien los primeros casos confirmados fueron personas llegadas de viajes al exterior, en las últimas semanas se han multiplicado las infecciones por transmisión local. Hasta el 6/4/2020 Latinoamérica acumulaba más de 27.000 casos confirmados y alrededor de 900 fallecidos, siendo a la fecha Brasil con
10.278 casos el país más afectado, seguido de Chile (4.161), Ecuador (3.465), Perú, Panamá, Argentina y México $^{7}$. La OMS ha descrito cuatro posibles escenarios de transmisión y ha sugerido planes concretos de acción clasificando a los países en cuatro categorías: Países sin casos registrados, con "primeros casos registrados", con "primeros focos identificados" y países con "transmisión comunitaria demostrada y en fase de diseminación". A la fecha actual, la mayoría de los países latinoamericanos pertenecen al último grupo, con una alta tasa de casos producto de transmisión local y un crecimiento rápido de contagios a nivel regional, particularmente en zonas tales como la región del Guayas en Ecuador y Sao Paulo, en Brasil (dos de los países más afectados) (tabla 1).

\section{Retos y oportunidades para América Latina frente a la pandemia por COVID-19}

La llegada "tardía" del virus a Latinoamérica en comparación con Asia y Europa, ha abierto una ventana de oportunidad que ha permitido a la mayoría de los países tomar medidas enérgicas tempranas tratando de frenar el avance de la pandemia (declaración de "estado de emergencia sanitaria" o "estado de excepción por catástrofe", promoción de medidas de higiene más rigurosas, búsqueda y contacto de casos sospechosos, restricción de la movilidad y aglomeraciones en las calles, cierre de escuelas y universidades, expendios de comida, bares, restaurantes, locales y centros comerciales, cuarentena voluntaria u obliga- 
Tabla 1. Casos acumulados COVID-19 por país, dentro del Continente Americano, según PAHO, al 29 de Marzo 2020

\begin{tabular}{|c|c|c|c|c|c|}
\hline Región & País & Casos confirmados & Casos Sospechados & Muertes & Transmisión \\
\hline \multirow[t]{4}{*}{ América del Norte } & Canadá & 5.655 & & 61 & Comunitaria \\
\hline & México & 848 & 2.623 & 16 & Comunitaria \\
\hline & Estados Unidos & 122.653 & & 2.112 & Comunitaria \\
\hline & Subtotal & 129.156 & 2.623 & 2.189 & \\
\hline \multirow[t]{8}{*}{ América central } & Belice & 2 & & & Casos esporádicos \\
\hline & Costa Rica & 295 & 34 & 2 & Grupos de casos \\
\hline & El Salvador & 24 & & & Casos esporádicos \\
\hline & Guatemala & 34 & 45 & 1 & Grupos de casos \\
\hline & Honduras & 110 & & 2 & Grupos de casos \\
\hline & Nicaragua & 4 & & 1 & Casos esporádicos \\
\hline & Panamá & 901 & & 17 & Comunitaria \\
\hline & Subtotal & 1.370 & 79 & 23 & \\
\hline \multirow[t]{11}{*}{ América del Sur } & Argentina & 745 & 2 & 19 & Grupos de casos \\
\hline & Bolivia & 74 & 16 & & Grupos de casos \\
\hline & Brasil & 3.904 & 11.278 & 114 & Comunitaria \\
\hline & Chile & 1.909 & & 6 & Comunitaria \\
\hline & Colombia & 608 & 184 & 6 & Grupos de casos \\
\hline & Ecuador & 1.835 & 2.680 & 48 & Comunitaria \\
\hline & Paraguay & 59 & & 3 & Grupos de casos \\
\hline & Perú & 671 & & 11 & Comunitaria \\
\hline & Uruguay & 303 & & & Grupos de casos \\
\hline & Venezuela & 113 & & 2 & Grupos de casos \\
\hline & Subtotal & 10.221 & 14.160 & 209 & \\
\hline
\end{tabular}

toria, toques de queda nocturnos, cierre de fronteras, suspensión de vuelos internacionales, uso obligatorio de mascarillas de protección para la población general, suspensión del transporte público y otras). De ser efectivas, estas medidas podrían contener la diseminación del virus, "aplanar la curva" de contagios y favorecer un uso racional de los recursos disponibles en materia de salud pública. Sin embargo, los retos a considerar son múltiples: 1) Mantener en cuarentena prolongada a una población mayoritariamente pobre que depende del trabajo diario para subsistir va a resultar difícil, aún sabiendo que sin cuarentena ni aislamiento social las tasas de transmisión serán muy altas y la duración de la pandemia podría prolongarse en el tiempo; 2) Anticipar la llegada del brote anual estacional de influenza y dengue que podría complicar el panorama epidemiológico de la región; 3) Prever los efectos sobre las tasas de contagio del descenso de las temperaturas con la llegada del invierno en los países del sur del continente; 4) Enfrentar un problema de salud pública de tal magnitud en un escenario de limitados recursos económicos podría comprometer la aplicación de adecua- das estrategias de prevención, la necesaria realización a gran escala de tests de diagnóstico rápido, lo cual se considera de vital importancia para rastrear el virus, comprender la epidemiología local y suprimir la transmisión; y, el adecuado cumplimiento de protocolos de tratamiento ambulatorio e intrahospitalario; 5) Asumir las consecuencias a mediano y largo plazo de las medidas antes mencionadas sobre economías vulnerables y en muchos casos ya comprometidas.

Surgen en medio de esta complicada situación algunas interrogantes relacionadas, en primer lugar, con la respuesta en el tiempo de la población latinoamericana expuesta al SARS-CoV-2. En términos generales se trata de una población más joven y con características demográficas, étnicas y bio-socio-culturales distintas a las poblaciones de Europa y Estados Unidos (por ejemplo, menos del 9\% de la población latinoamericana es mayor a los 65 años, en comparación con $20 \%$ de la población europea y $16 \%$ de la población norteamericana). ¿Podríamos esperar un comportamiento similar de la pandemia en nuestro continente a lo que está ocurriendo en los países europeos y en Norteamérica? En 
segundo lugar, es difícil predecir las reales consecuencias de esta pandemia en el futuro de la región. ¿Podrá América Latina soportar la carga que un problema de salud pública como este representará para sus sistemas de salud y las consecuencias económicas a mediano y largo plazo si la situación se prolonga en el tiempo?. Aunque las respuestas a estas interrogantes están lejos de estar claras, algo en lo cual todos coincidimos es que debemos prepararnos para librar una batalla para la cual necesitaremos de apoyo financiero y cooperación internacional, asesoría en materia de salud pública por parte de grupos de expertos, sociedades científicas y organismos nacionales e internacionales competentes, una intensa labor de educación y asistencia financiera para la población general y tal vez lo más importante, el concurso y la adecuada protección de nuestro recurso más preciado: el talento, entrenamiento, experiencia, mística de trabajo y conocimiento de nuestros académicos, científicos, investigadores y de todo el personal de salud (médicos, enfermeras, paramédicos, etc.) que como ha quedado demostrado ya en otros países, constituyen el mejor recurso y la herramienta más valiosa en la lucha para limitar los alcances de la pandemia por COVID-19.

\section{Conflicto de intereses}

Los autores declaran no tener conflicto de intereses.

\section{Referencias}

1. Bedford J, Enria D, Giesewcke J, et al. COIVD-19: towards controlling of a pandemic. The Lancet 2020; 395(10229):1015-8.

2. Guan W, Ni Z, Hu Y, et al. Clinical characteristics of coronavirus disease 2019 in China. N Engl J Med 2020, Feb 28. DOI:10.1056/NEJMoa2002032.

3. Pan L, Mu M, Ren HG, et al. Clinical Characteristics of COVID-19 Patients with Digestive Symptoms in Hubei, China: A descriptive, cross- sectional, multicenter study. Am J Gastroenterol 2020, Mar 19 (E Pub Ahead of Print).

4. Xiao F, Tang M, Zheng X, Liu Y, Li X, Shan H. Evidence for gastrointestinal infection of SARSCoV-2. Gastroenterology 2020; S00165085(20)30282-1.

5. Wu Z, McGoogan JM. Characteristics of and important lessons from the coronavirus disease 2019 (COVID-2019) outbreak in China: summary of a report of 72314 cases from the Chinese Center for Disease Control and Prevention.
JAMA 2020 February 24 (Epub ahead of print).

6. Lu X, Zhang L, Du H, et al. SARS-Co-V-2 Infection in Children (Correspondence). DOI:10.1056/ NEJMc2005073.

7. Dong E, Du H, Gardner L. An interactive web-based dashboard to track COVID-19 in real time. Published Feb. 19, 2020. DOI: https://doi.org/10.1016/S14733099(20)30120-1.

8. World Health Organization. Coronavirus disease (COVID-19) outbreak. Situation report 57.2020. 